\title{
An extension of the streamline curvature through-flow design method for bypass fans of turbofan engines
}

J Aerospace Engineering

$0(0) \mathrm{I}-14$

(C) IMechE 2016

Reprints and permissions:

sagepub.co.uk/journalsPermissions.nav

DOI: 10.1177/0954410016636159

uk.sagepub.com/jaero

@SAGE

\author{
Sercan Acarer' and Ünver Özkol ${ }^{2}$
}

\begin{abstract}
The two-dimensional through-flow modeling of turbomachinery is still one of the most powerful tools available to the turbomachinery industry for aerodynamic design, analysis, and post-processing of test data due to its robustness and speed. Although variety of aspects of such a modeling approach are discussed in the publicly available literature for compressors and turbines, not much emphasis is placed on combined modeling of the fan and the downstream splitter of turbofan engines. The current article addresses this void by presenting a streamline curvature through-flow methodology that is suitable for inverse design for such a problem. A new split-flow method for the streamline solver, alternative to the publicly available analysis-oriented method, is implemented and initially compared with two-dimensional axisymmetric computational fluid dynamics on two representative geometries for high and low bypass ratios. The empirical models for incidence, deviation, loss, and end-wall blockage are compiled from the literature and calibrated against two test cases: experimental data of NASA two-stage fan and three-dimensional computational fluid dynamics of a customdesigned transonic fan stage. Finally, experimental validation against GE-NASA bypass fan case is accomplished to validate the complete methodology. The proposed method is a simple extension of streamline curvature method and can be applied to existing compressor methodologies with minimum numerical effort.
\end{abstract}

\section{Keywords}

Gas turbine, jet engine, turbofan, bypass, split-flow, fan, through-flow, streamline curvature, loss correlation, transonic

Date received: 7 July 2015; accepted: 29 January 2016

\section{Introduction}

Internal turbomachinery flows are among the most complex aerodynamic problems due to complex three-dimensional (3D) nature of the flowfield and high level of interaction between aerodynamic surfaces. In this regard, complexity of designing a turbomachinery system is traditionally overcome by use of reduced-order models at the beginning of design, and then progressively increasing fidelity through the end of design. ${ }^{1}$ The amount of design modifications usually becomes smaller as fidelity increases; to the author's experience, around $80 \%$ of the design is fixed during 1D and 2D modeling phases. ${ }^{2}$ Twodimensional through-flow modeling, which is usually attributed to quasi-3D approach of $\mathrm{Wu}^{3}$ is a key element within in this hierarchy. It both embodies the simplicity of 1D models and the high fidelity of 3D models. Basically, the effects of blades are imposed into an axisymmetric swirling compressible flow solution as local sources by employing turbomachine energy equation and empirical data of turning, pressure loss, and blockage. Through-flow definition is so powerful that rapid simulation of the principal aspects of turbomachinery flow becomes possible, and inverse design, off-design analysis, and postprocessing of test data may be performed within this approach. ${ }^{1}$ Moreover, past experience can easily be implemented through these sources, which is quite time consuming during 3D Navier-Stokes simulations.

Through-flow methods in the literature are built around many types of axisymmetric flow solvers, i.e. streamline curvature method of solution (SLC), pioneered by Smith $^{4}$ and Novak, ${ }^{5}$ matrix method, ${ }^{6}$ finite element method, ${ }^{7,8}$ finite volume Euler, ${ }^{9-12}$ and Navier-Stokes ${ }^{13}$ methods. Among these, SLC is one of the most prevalent methods ${ }^{14}$ because of its simplicity, robustness, ability to cope with supersonic machines, ${ }^{15,16}$ and definition of the physical

\footnotetext{
'R\&D Department, Tusaş Engine Industries, Eskişehir, Turkey ${ }^{2}$ Mechanical Engineering Department, İzmir Institute of Technology, İzmir, Turkey
}

\section{Corresponding author:}

Sercan Acarer, R\&D Department, Tusaş Engine Industries, Esentepe Mh. Çevreyolu Blv. No. 356, Tepebaşı 26003, Eskişehir, Turkey. Email: sercanacarer@gmail.com 
properties on axisymmetric streamlines, which is a practical advantage in airfoil design.

Fans are principally very similar with compressors; therefore, they are characterized by flowfields that are dominated by adverse pressure gradients and thick boundary layers. This, together with the presence of hub and shroud end-walls, results in strong dependency of solution on the empirical databases. ${ }^{1}$ Although the models or data used by organizations are mostly confidential, there are publicly open correlations for standard airfoil profiles, as reviewed by Hirsch and Denton ${ }^{17}$ and Çetin et al. ${ }^{18}$ Lieblein, ${ }^{19}$ Lieblein et al., ${ }^{20}$ Miller et al. (MLH) ${ }^{21}$ are the classical correlations for incidence/deviation angles, friction losses, and shock losses, respectively, which form baseline to many correlations. The more recent Koch and Smith $^{22}$ correlations may also be classified as the principle alternative to those correlation sets. In addition, blockage effects are among biggest sources of errors, especially in matching of multistage compressors, because of small annulus areas and highly thickened complex boundary layers and wakes. Those effects were initially taken into account by simply assigning empirical effective area coefficients, nonetheless empirical models to estimate blockage effects are also available, some examples were presented by Horlock. ${ }^{23}$ A leap forward in accuracy is achieved by the inclusion of $3 \mathrm{D}$ spanwise mixing effects that is mainly studied by Adkins and Smith, ${ }^{24}$ Gallimore, ${ }^{25}$ Wisler et al., ${ }^{26}$ and Dunham. ${ }^{27}$ Those models eliminate unrealistic accumulation of low energy flow in the end wall regions and diffuse them to the main flow. Mönig et al. $^{28}$ enhanced this correlation by taking into account the local details of the boundary layer for a SLC through-flow methodology. Finally, the above-cited MLH model is known to be insufficient to estimate shock losses in the tip regions of modern high-speed fans or compressors. Improvements by Wennerstrom $^{29}$ and Boyer $^{30}$ are among major enhancements in this area.

Although much research has been conducted on SLC-based through-flow models, not much emphasis is placed in the open literature on fan modeling with downstream splitter and ducts. To the author's best knowledge, the principle method for such a problem is the one presented by Novak, ${ }^{5}$ who built a solution scheme around iterative solutions of sub-domains. Initial guess of the stagnation streamline, which stagnates at the splitter leading edge and fixes bypass ratio, is improved through iterations until convergence with it and all other streamlines are achieved. Although this is a universal method of solution, it potentially seems more suitable for direct (analysis) mode because the stagnation streamline may easily approach to the splitter at an off-design angle of attack for a given bypass ratio. Another more recent method is presented by Shan, ${ }^{31}$ who artificially models the effect of splitter through modified stream tube mass flows and blockage factors. Nevertheless, it can be applied to certain geometries and is not a general method of solution. Remaining related studies mostly consider single-stream fans, decoupled from the splitter. However, limited number of studies, such as Calvert and Stepleton, ${ }^{32}$ Karadimas, ${ }^{33}$ and Sullivan et al., ${ }^{34-36}$ consider bypass fans, but do not really touch details of the modeling approach itself.

The present study addresses this gap by developing a complete and alternative inverse-design oriented SLC methodology, including both split-flow capability and calibrated empirical models.

\section{Streamline curvature method}

Streamline curvature method is based on inviscid Euler equations that is cast in intrinsic coordinates. The flow is assumed as axisymmetric, adiabatic, inviscid, and compressible. With these assumptions, the original set of equations reduces to one momentum equation along a pre-defined direction $(q)$ that is approximately normal to the streamlines ${ }^{15}$

$$
\begin{aligned}
V_{m} \frac{\partial V_{m}}{\partial q}= & \frac{\partial H}{\partial q}-T \frac{\partial s}{\partial q}-\frac{V_{\theta}}{r} \frac{\partial\left(r V_{\theta}\right)}{\partial q}+V_{m} \sin \varepsilon \frac{\partial V_{m}}{\partial m} \\
& -K_{m} V_{m}^{2} \cos \varepsilon-F_{q}
\end{aligned}
$$

Computational nodes are the intersections of initially unknown but estimated streamlines with prescribed quasi-orthogonals (QO) (Figure 1). The streamlines float on QOs and the estimates are continuously being updated using stream tube continuity. The streamline curvature $\left(K_{m}\right)$ and the angle between true and quasi-orthogonal $(\varepsilon)$ (Figure 1) are the key parameters, which must be estimated locally. The equation must be accompanied by continuity (with local effective area coefficient for blockage) and thermodynamic state equations for solution within the duct (blade-free) regions. In the trailing edges of blade rows, the turbomachinery energy equation and empirical data for the gap between the leading and trailing edges must additionally be used for each streamline (or for each cross section) to obtain local $H, P_{T}, T_{T}, s, V_{\theta}$, and blockage values. In between the leading and trailing edges, other than considering the metal blockage effects, streamwise distributions of loss and turning may be specified based on experience. ${ }^{29}$ The current methodology arbitrarily assumes linear streamwise variation of $s$ and $V_{\theta}$, although any other distribution may be specified for better interblade accuracy. The solution is highly iterative due to the non-linear nature of the problem. Details of the SLC theory are well established and may be found in the open literature. , 15,37 $^{-1}$

Direct (a.k.a. analysis) mode of solution implies that the relative flow angle distributions at the blade trailing edges are specified from a known geometry and the corresponding $V_{\theta}$ values are obtained using relative flow angle and meridional velocity $\left(V_{m}\right)$. Inverse (a.k.a. design) mode of solution, which is 


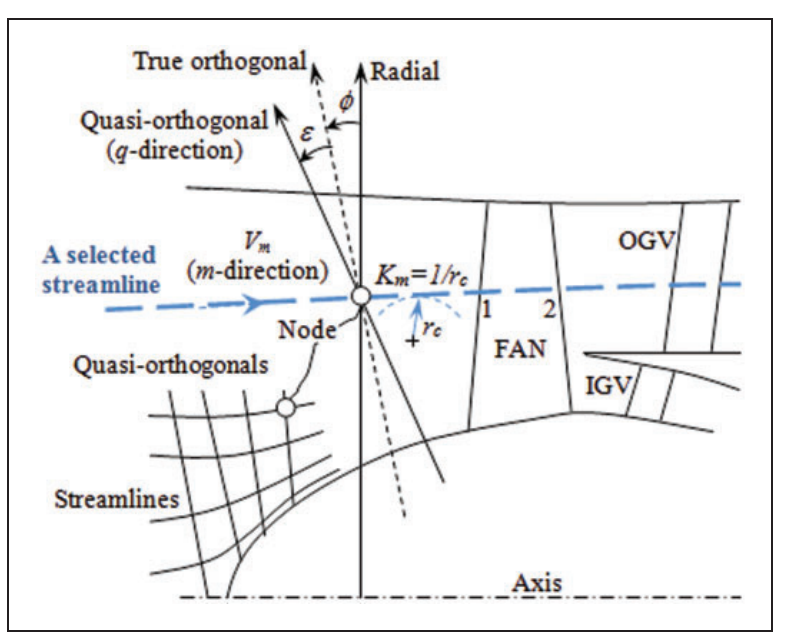

Figure I. Streamline curvature method.

implemented in this study, implies that $V_{\theta}$ distributions at the trailing edge of each blade row (similarly $H$ or indirectly total pressure) are specified as a design requirement and the corresponding flow angle distributions are sought.

\section{Proposed flow-splitter scheme}

The proposed method for split-flow modeling is based on the fact that upstream propagation of any downstream obstacle in a SLC model is taken into account mostly by geometrical means, i.e. by $\varepsilon$ and $K_{m}$ terms of equation (1), as well as $\delta V_{m} / \delta m$ term.

As depicted in Figure 2(b), the computational domain is divided into three sub-domains such as fan (domain 1), bypass (domain 2), and core (domain 3). The initially specified hub, shroud, and splitter contours (flowpaths) remain fixed during the solution. The fan domain outlet, which is a quasiorthogonal, coincides with the splitter leading edge to form an interface with bypass and core domains. First step is to guess a combined streamline network, where a unique streamline just above the splitter is identified. Therefore an initial guess for distribution of inlet streamlines into bypass and core ducts is established. Unlike the conventional method of Novak $^{5}$ (Figure 2(a)), final form of this distribution is unknown and there is no stagnation streamline. Consecutive solutions of fan, bypass, and core domains are carried out such that streamlines of the unified domain are considered, rather than considering only limited sections of streamlines (intersections of the unified streamlines with each sub-domain). As an inherent consequence, the streamline terms in equation (1) $\left(K_{m}\right.$ and $\left.\varepsilon\right)$, hence the streamline curvature effects, are treated correctly. The streamline adjustments (the outer loop iteration) are performed for all domains simultaneously after the completion of each subsequent fan, bypass and core solutions. During these iterations, the specific streamline that is just above the flow splitter (the innermost bypassing streamline other than the splitter wall itself) can change. Therefore, the distribution of streamlines to bypass and core ducts can change. The procedure continues until convergence with streamline adjustments is achieved. The procedure is charted in Figure 3.

Although the presented method is principally very similar with the conventional method applied by Novak, ${ }^{5}$ the bypass ratio comes out as a result of the present calculation whereas it is an input for the former method and streamlines will always approach to the splitter at the design angle of attack.

\section{Turbomachinery models}

The fundamental Euler turbomachinery equation is utilized to obtain total enthalpy rise along each cross section of each blade row (simply section)

$$
H_{2}-H_{1}=\omega\left[\left(r V_{\theta}\right)_{2}-\left(r V_{\theta}\right)_{1}\right]
$$

The corresponding discharge (absolute and relative) total temperatures and total pressures may easily be obtained using the well-known isentropic ideal gas relations. The relative total pressure loss coefficient $\left(\varpi_{P T}\right)$ is used to estimate the actual discharge relative total pressure ${ }^{37}$

$$
P_{T 2}^{\prime}=\left(P_{T 2}^{\prime}\right)_{\text {isentropic }}-\varpi_{P T}\left(P_{T 1}^{\prime}-P_{S 1}\right)
$$

Where pressure loss coefficient is a combination of friction (profile + secondary) and shock loss coefficients. Tip leakage loss is not modeled, similar to Wennerstrom; ${ }^{29}$ it is lumped into the shock loss coefficient through the calibration process. In the design mode, incidence and deviation models are also required to obtain inlet and outlet metal angles from the flow angles.

\section{Empirical models}

Complete list of the utilized models, together with the references, are listed in Table 1 . Key aspects of those models are described in the following text.

Reference (incompressible) minimum loss incidence $\left(i^{*}\right)$ and the corresponding flow deviation $\left(\delta^{*}\right)$ are obtained from the well-known Lieblein models. ${ }^{19,38}$ Once the reference minimum loss incidence is obtained, reference stall and choke angular ranges are estimated to establish compressibility corrections. The range from design incidence to choke incidence $\left(i_{c}\right)$, denoted as $R_{c}$, can be estimated as a function of camber $(\theta)$, inlet metal angle $\left(K_{1}\right)$ and max. thickness-to-chord $\operatorname{ratio}(t h / c)$ by ${ }^{39}$

$$
i_{c}-i^{*}=-R_{c}=-\left(10-\theta \frac{\left(K_{1}-40\right)}{450}\right)\left(0.5+5 \frac{t h}{c}\right)
$$




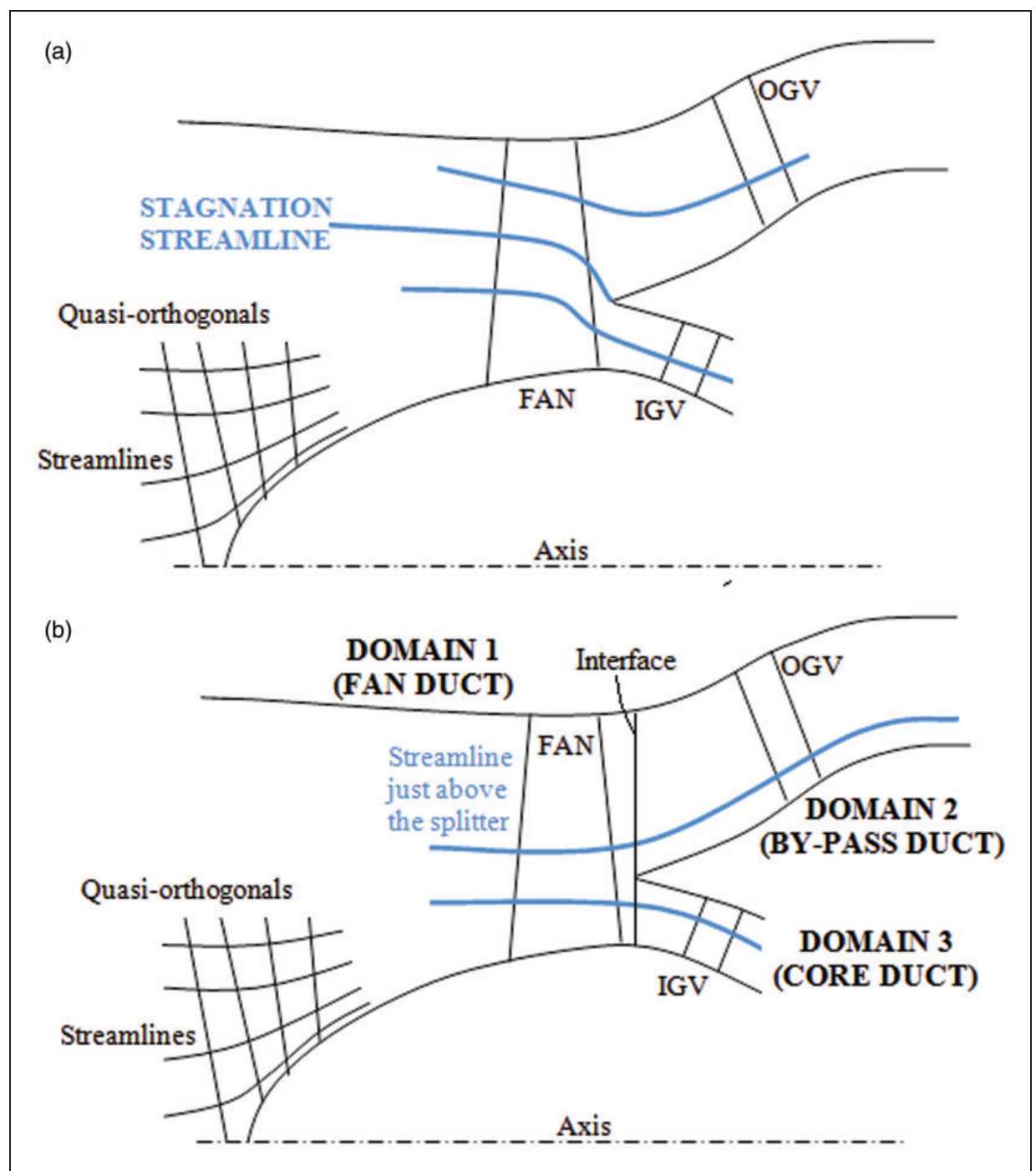

Figure 2. Conventional ${ }^{5}$ (a) and developed (b) split-flow methods.

Similarly, reference range from design incidence to stall incidence $\left(i_{s}\right)$, denoted as $R_{s}$, can be estimated by

$$
i_{s}-i^{*}=R_{s}=1.5\left(10+\theta \frac{\left(55-K_{1}\right)}{150}\right)\left(0.5+5 \frac{t h}{c}\right)
$$

These ranges narrow considerably as the inlet Mach number increases. Aungier ${ }^{37}$ suggest below corrections for compressibility effects

$$
\begin{aligned}
& i_{c \text { (compressible })}=i^{*}-R_{c} /\left[1+0.5\left(M_{1}^{\prime}\right)^{3}\right] \\
& i_{s(\text { compressible })}=i^{*}+R_{s} /\left[1+0.5\left(K_{s h} M_{1}^{\prime}\right)^{3}\right]
\end{aligned}
$$

An additional limit is activated for $i_{c}$ such that it must be higher than the real choke incidence, which will result in $2 \%$ more mass flow rate than the choke mass flow of the section (according to Aungiers practice $\left.^{37}\right)$. This limit results

$$
i_{c(\text { compressible })}=\beta_{1 \text { choke }}-K_{1}+1^{o}
$$

where $\beta_{1 \text { choke }}$ is the flow angle at which passage chokes at the throat. It may be estimated from

$$
\rho_{1} W_{1} t \cos \left(\beta_{1 \text { choke }}\right)=o \rho_{\text {sonic }} W_{\text {sonic }}
$$

where " $o$ " is the throat opening, " $t$ " is the pitch and the subscript "sonic" denotes sonic conditions, which can be obtained using thermodynamic state equation and inlet total pressure and temperature.

Throat opening (geometric throat) should ideally be obtained from the actual airfoil shape, where possible, due to reliability problems of correlations, ${ }^{37}$ but it is unknown during the design phase since it changes rapidly with continuously updated velocity triangles during the solution. Therefore, empirical formulas given by Aungier ${ }^{37}$ are implemented to estimate the "potential" or "design" throat-to-pitch ratio

$$
o / t=[(1-t h \sqrt{\sigma} / c) \cos \psi]^{\sqrt{\sigma}}
$$




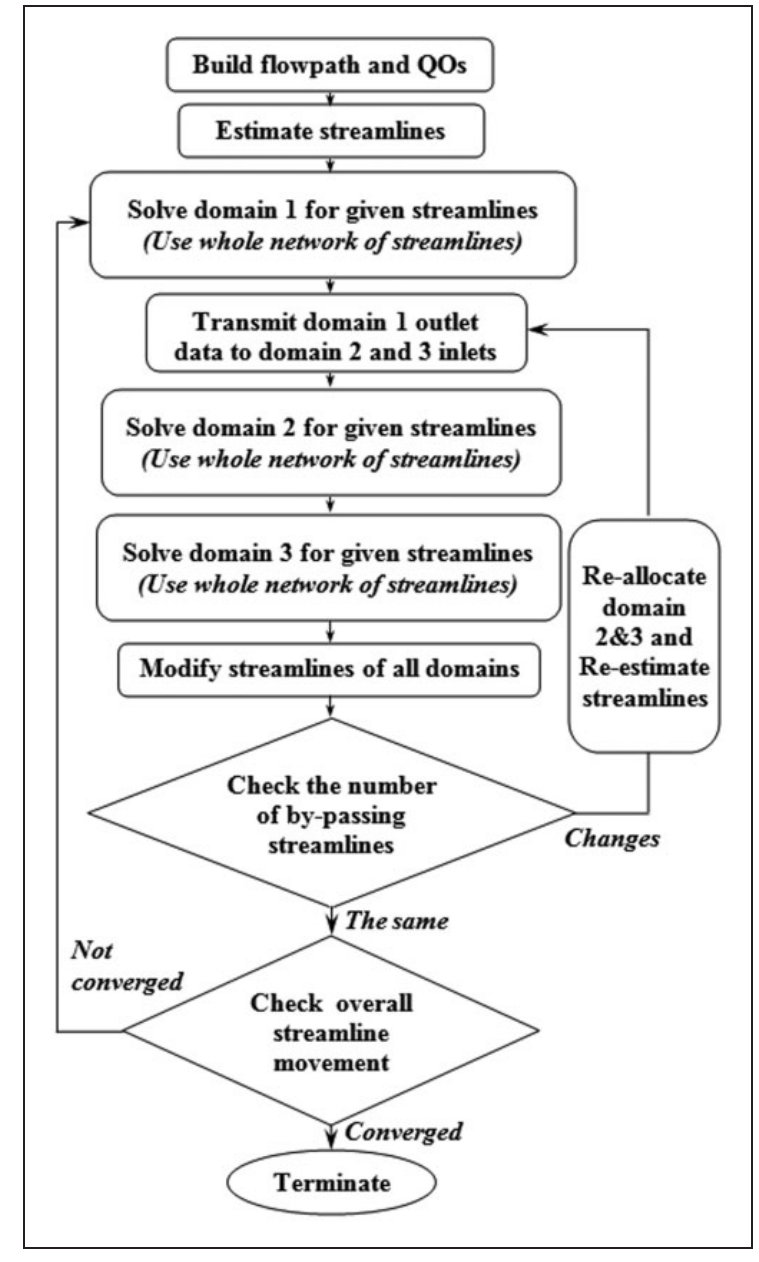

Figure 3. Split-flow algorithm.

where $\psi$ is modified stagger parameter defined as

$$
\psi=\gamma\left[1-\frac{1}{20}\left(\frac{\tan \left(\frac{\theta}{4}\right)}{0.05515} \frac{a}{c}\right)^{1.5}\right]+5\left(\frac{\tan \left(\frac{\theta}{4}\right)}{0.05515} \frac{a}{c}\right)^{1.5}-2
$$

This formula takes into account the chord-wise location of maximum camber point $(a / c)$ by assuming parabolic camberline, ${ }^{37}$ rather than simpler circular camberline.

Within the parabolic camberline assumption, the ( optimum) stagger can be estimated by

$$
\gamma=K_{1}-\arctan \left[4 \frac{b}{c} /\left(4 \frac{a}{c}-1\right)\right]
$$

In this equation, $b$ is the maximum distance between the camberline and the chordline, which is at the position corresponding to $a / c . b / c$ ratio is given by ${ }^{37}$

$$
\frac{b}{c}=\left\{\sqrt{1+(4 \tan \theta)^{2}\left[\frac{a}{c}-\left(\frac{a}{c}\right)^{2}-\frac{3}{16}\right]}-1\right\} / \tan (\theta)
$$

Finally, Mach-corrected minimum loss incidence is obtained by ${ }^{37}$

$$
i_{m}=i_{c}+\left(i_{s}-i_{c}\right) R_{c} /\left(R_{c}+R_{s}\right)
$$

For the deviation $\left(\delta^{*}\right)$, a correction is also applied for meridional acceleration or deceleration, which has a significant impact ${ }^{30}$

$$
\delta_{V_{m}}=10\left(1-V_{m 2} / V_{m 1}\right)
$$

Inlet relative Mach number effects are not applied as it has a minor impact on the deviation; ${ }^{30}$ however, three-dimensional effects are considered during calibration process (the next section).

The total pressure loss coefficient, defined by equation (3), is composed of friction (profile+secondary) and shock loss coefficients. The friction loss coefficient is based on NASA SP-36 loss correlations, ${ }^{38}$ defined by

$$
\varpi^{*}=\frac{2 \sigma C_{1}\left[C_{2}+3.1\left(D_{e q}-1\right)^{2}+0.4\left(D_{e q}-1\right)^{8}\right]}{\cos \left(\beta_{2}\right)}\left(\frac{W_{2}}{W_{1}}\right)^{2}
$$

where $C_{1}$ and $C_{2}$ are calibration coefficients and $\sigma$ is solidity. $C_{1}$ is taken as $0.0073,{ }^{37}$ while $C_{2}$ considers the secondary loss effects by ${ }^{37}$

$$
C_{2}=1+\left(t_{\text {average }} / h\right) \cos \beta_{2}
$$

The friction loss coefficient, defined by equation (16), is corrected for Mach number effects as

$$
\varpi_{P T-\text { friction }}=\varpi^{*}\left[1+\left(i_{m}-i^{*}\right)^{2} / R_{s}^{2}\right]
$$

Shock losses are considered both for transonic-inlet and supersonic-inlet sections. For transonic-inlet sections, below relation is used ${ }^{37}$

$$
\varpi_{P T-\text { shock(transonic })}=K_{\text {sh }}\left[\left(M_{1}^{\prime} / M_{\text {critical }}-1\right) W_{\text {sonic }} / W_{1}\right]^{2}
$$

For supersonic-inlet sections, MLH model ${ }^{21}$ is used as a baseline to calculate shock losses $\left(\varpi_{P T \text { - }}\right.$ shock(supersonic)). The model assumes a single normal shock at upstream Mach number calculated as the geometric $^{37}$ average of inlet relative Mach number and accelerated suction surface Mach number. Wennerstrom $^{29}$ model is utilized to consider 3D obliqueness to modify the average Mach number.

\section{Calibration of the empirical models}

Some modifications to the above cited correlations are applied according to preliminary calculations on NASA two-stage fan and the custom-designed fan 
Table I. Summary of the utilized empirical models.

\begin{tabular}{ll}
\hline Reference minimum-loss incidence & Lieblein $^{19}$ or NASA SP-36 $^{38}$ \\
Ref. stall-choke incidence range & Kleppler $^{39}$ \\
Optimum stagger & Aungier $^{37}$ \\
Throat & Aungier $^{37}$ \\
Mach corrected stall-choke range & Aungier $^{37}$ \\
Mach corrected min. loss incidence & Aungier $^{37}$ \\
Reference deviation & Lieblein $^{19}$ or NASA SP-36 $^{38}$ \\
Deviation correction & Boyer $^{30}$ \\
Equivalent diffusion factor & Koch and Smith $^{22}$ \\
Friction (profile+secondary) loss coefficient & Aungier $^{37}$ (based on NASA SP-36 $^{38}$ ) \\
Transonic shock loss coefficient & Aungier $^{37}$ \\
Supersonic shock loss coefficient & Miller et al. $^{21}$ and Wennerstrom \\
End-wall blockage & Pachidis $^{40}$ \\
Off-design loss & Çetin et al. $^{18}$ \\
Off-design deviation & Creveling $^{41}$ \\
\hline
\end{tabular}

stage, which are single-stream transonic fan test cases and presented in the validation section. The split-flow GE-NASA transonic fan test case, which is also introduced in the validation section, is not considered during the calibration process. Below items are the extensions made to the original correlations:

1. The pitch of a section is mainly used for shock loss and throat estimations (see the previous section). As these are typically located close to leading edges for fans and compressors, ${ }^{1}$ it seems reasonable to consider inlet pitch of each section. On the other hand, the solidity mainly determines viscous losses, hence average solidity should be considered for each section. Although a historical justification could not be found in the open literature, the authors experienced better performance with these settings in the investigated cases.

2. In case there is overturning, where outlet metal angle sign is different than the inlet metal angle sign (as seen in front stage fan roots), the outlet metal angle is taken as zero in camber terms of the reference incidence correlation and equation (11).

3. For the transonic shock losses given by equation (19), the exponent " 2 " is made " 1.6 " to better match the test cases. This should be reasonable since Aungier ${ }^{37}$ developed this correlation for double-circular-arc (DCA) profiles, but the investigated three test cases have multiple-circular-arc (MCA) or MCA-like (section "GE bypass fan system") profiles, which have lower shock losses compared to DCA. ${ }^{1}$ The improvement at and below the sonic line in Figure 14 is partly achieved by this modification.

4. The suction surface (Prandtl-Mayer) supersonic expansion angle for supersonic-inlet shock losses are originally predicted for circular camberlines. ${ }^{37}$ This value is multiplied by 0.95 for inlet relative Mach numbers lower than 1.25 and multiplied by
0.45 for inlet relative Mach numbers bigger than 1.4. Linear variation is assumed in between inlet Mach numbers of 1.25 and 1.4. This correction is to model wedge or pre-compression blade profiles where the expansion is less than that occurs for circular arc camberlines.

5. The deviation correlation is also calibrated relative to the test cases to include $3 \mathrm{D}$ effects. Reducing the deviation by $1^{\circ}$ resulted in good results. Moreover, as trend-wise similar to Petrovic et al., ${ }^{8}$ the rotor tip section deviation is increased by $2^{\circ}$ to take into account tip leakage effects (over $-1^{\circ}$ ) and the correction linearly reduces to $0^{\circ}$ at $90 \%$ span from hub. For the GE-NASA bypass fan case, there are strong 3D effects in the hub, due to excessive overturning and wall ramp angle, which may affect deviation. As applied in the original design report, ${ }^{34}$ an additional $6^{\circ}$ deviation is applied at the hub, which linearly diminishes to zero at $45 \%$ span.

\section{Validation of the complete methodology}

Validation of the developed methodologies is accomplished in three steps: Firstly, split-flow solution of the developed method for two duct geometries of different bypass ratios, but without a turbomachinery, is compared as a sanity check with 2D computational fluid dynamics (CFD). Secondly, NASA two-stage fan and a custom-designed transonic fan stage results are used to validate the empirical models for generic single-stream transonic fan cases (as a result of the aforementioned calibration process). Thirdly, experimental validation with GE-NASA advanced bypass fan test case is used to validate the complete models, both the new split-flow modeling and the empirical models. 


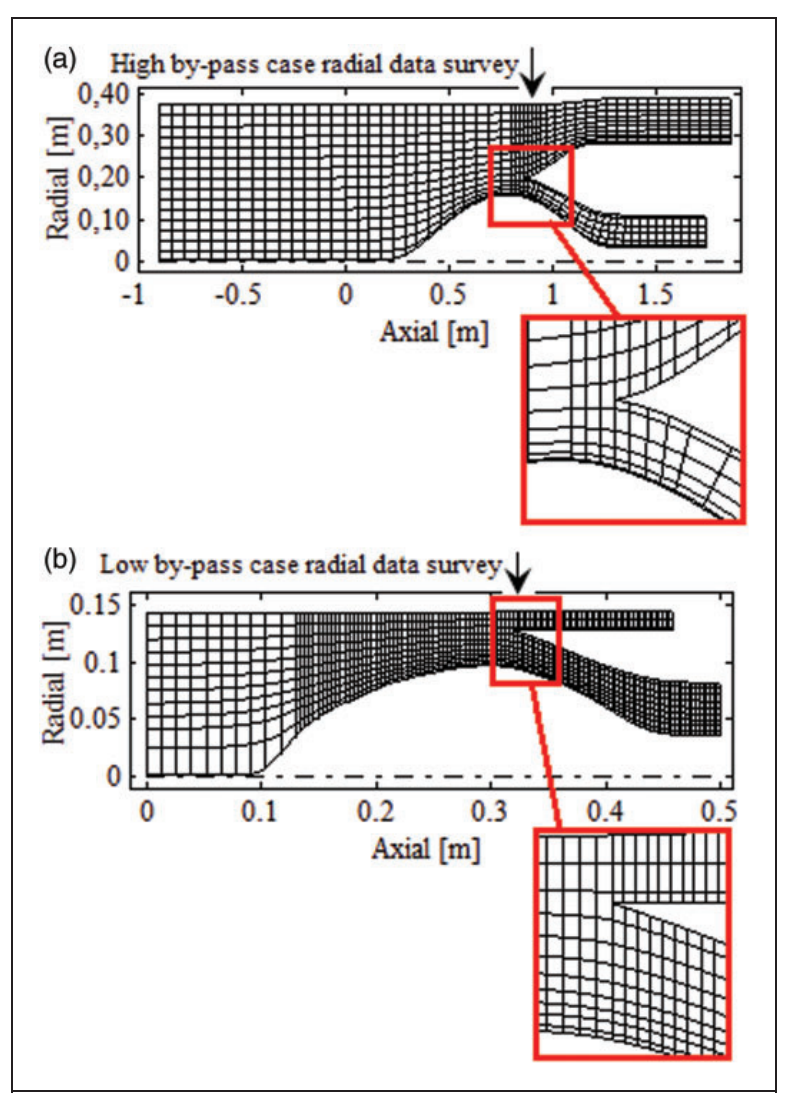

Figure 4. Computational grid for the high (a) and low (b) bypass cases.

\section{Two-dimensional validation of the split-flow method}

This section intents the preliminary verification of split-flow methodology that is implemented to the streamline curvature methodology. In this regard, the subsonic compressible solutions of both a commercial finite volume software (Fluent) and the developed SLC solver on two rather aggressive split-flow duct geometries of high (7.2) and low (0.5) bypass ratios (HBP and LBP, respectively) are compared. The geometries and SLC grids for the both cases are presented in Figure 4, where only one-fourth of streamlines are visible. Standard sea-level static conditions $(101,325 \mathrm{~Pa}$ and $288.15 \mathrm{~K})$ and mass flows given in Table 2 are specified at the inlet (outlet conditions are outputs). The outputs of the commercial CFD software are assessed to be reliable considering only inviscid mode of solution is considered and the software is validated against many generic cases. ${ }^{42}$ The comparisons for the both cases are presented in Table 2 and Figure 5. Very good agreement is observed, indicating the validity of the SLC solver on split-flow ducts.

\section{NASA two-stage fan}

This section, as a part of the second phase of the validation effort, aims to validate the calibrated empirical correlations that are presented in
Table 2. Overall results.

\begin{tabular}{lccc}
\hline & CFD & SLC & Difference \\
\hline High bypass case $(\mathrm{HBP})$ & & & \\
Bypass mass flow $(\mathrm{kg} / \mathrm{s})$ & 184.4 & 184.4 & $0.01 \%$ \\
Core mass flow $(\mathrm{kg} / \mathrm{s})$ & 25.6 & 25.6 & $0.01 \%$ \\
Total mass flow $(\mathrm{kg} / \mathrm{s})$ & 210 & 210 & $0.01 \%$ \\
Bypass ratio & 7.2 & 7.2 & $-0.00 \%$ \\
Low bypass case (LBP) & & & \\
Bypass mass flow $(\mathrm{kg} / \mathrm{s})$ & 1.7 & 1.7 & $0.01 \%$ \\
Core mass flow $(\mathrm{kg} / \mathrm{s})$ & 3.4 & 3.4 & $0.01 \%$ \\
Total mass flow $(\mathrm{kg} / \mathrm{s})$ & 5.1 & 5.1 & $0.01 \%$ \\
Bypass ratio & 0.5 & 0.5 & $0.00 \%$ \\
\hline
\end{tabular}

CFD: computational fluid dynamics; SLC: streamline curvature method.

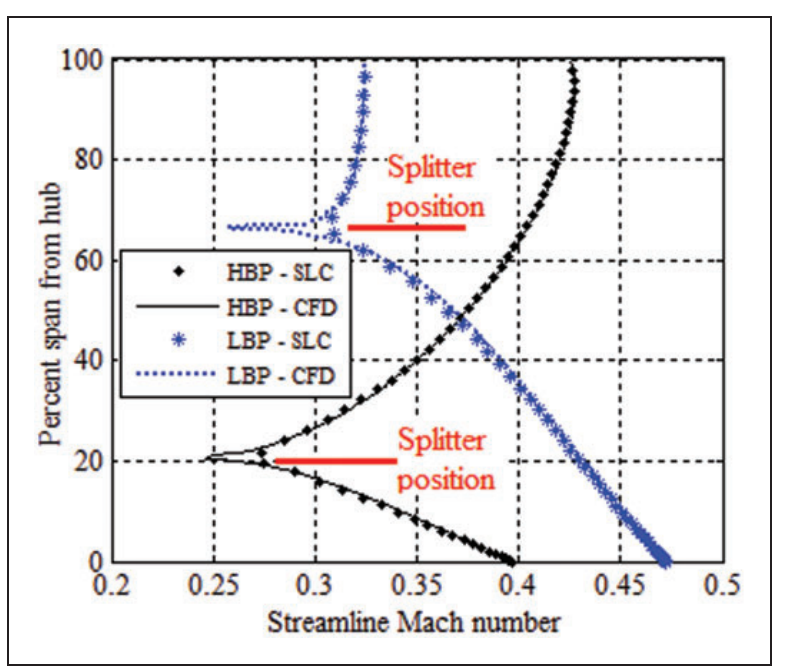

Figure 5. Comparison of the results at the radial data surveys.

"Turbomachinery models" section by NASA twostage fan test case, ${ }^{43}$ together with the customdesigned fan stage of the next section.

The SLC grid and meridional view of the fan is presented in Figure 6. Standard sea-level static conditions and the mass flow given in Table 3 are specified at the inlet and the calibrated (C) models described in section "Turbomachinery models" are used. The first stage rotor and tip sections of the second-stage rotor are made of multiple-circular-arc (MCA) profiles, where maximum camber locations are shifted rearwards to reduce supersonic expansion. Lower sections of second stage rotor and stators are made of doublecircular-arc (DCA) profiles.

Only the peak-efficiency experimental data at $100 \%$ design speed, which is defined at Table 3, is considered as it is closest to the intended design point. The under-predicted untwist of the first rotor caused higher than intended mass flow rate $(34.03 \mathrm{~kg} / \mathrm{s}$ instead of $33.25 \mathrm{~kg} / \mathrm{s}$ ), which caused off-design operation. 


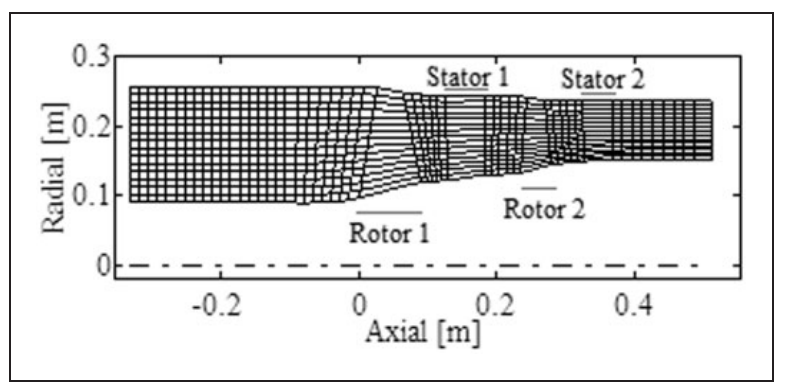

Figure 6. Computational grid of NASA two-stage fan.

Table 3. Overall results.

\begin{tabular}{lccl}
\hline & Test & SLC & Error (\%) \\
\hline Mass flow $(\mathrm{kg} / \mathrm{s})$ & 34.03 & 34.03 & 0 (imposed) \\
Total pressure ratio & $2.47 \mathrm{I}$ & 2.510 & 1.58 \\
Efficiency & 84.6 & 86.5 & 2.3 \\
\hline
\end{tabular}

SLC: streamline curvature method.

Table 4. Average errors of radial parameters.

\begin{tabular}{lccc}
\hline & Exit $V_{m}(\%)$ & Exit angle $\left(^{\circ}\right)$ & $\begin{array}{c}\text { Total pressure } \\
\text { ratio }(\%)\end{array}$ \\
\hline Rotor I & 3.0 & 0.6 & 0.9 \\
Stator I & 3.0 & 0.2 & - \\
Rotor 2 & 4.9 & 1.3 & 1.8 \\
Stator 2 & 7.6 & 0.3 & - \\
\hline
\end{tabular}

Measurement uncertainties are reported to be $\pm 0.3 \mathrm{~kg} / \mathrm{s}$ in mass flow rate, \pm 30 in $\mathrm{r} / \mathrm{min}, \pm 1^{\circ}$ in flow angle, $\pm 0.6 \mathrm{~K}$ in temperature and $\pm 0.7-1.7 \mathrm{kPa}$ in total pressure. The confidence level and uncertainties due to data reduction method are not reported. ${ }^{43}$

Comparisons of the overall results between SLC prediction and experiments are presented in Table 3, where good agreement is observed. In the comparisons, rather detailed airfoil features such as maximum camber location is also taken into account as described in "Empirical models" section. Table 4 presents a more detailed look into the errors in spanwise profiles, defined by the average of $100 \mathrm{x} \mid \mathrm{X}_{\mathrm{SLC}}-\mathrm{X}_{\text {test }} \mathrm{t} /$ $X_{\text {test }}$, where " $X$ " represents either of meridional velocity, exit relative flow angle or rotor pressure ratio. Inner and outer 5\% span, where viscous effects are dominating and test data is not available, are excluded in this comparison. According to those results, a good agreement is observed for the first stage, but discrepancies are bigger for the second stage, i.e. pressure ratio in the second rotor (Figure 7) and meridional velocity in the second stator (Figure 9(b)). It is expected that these are due to secondary flow effects and a rather simple model, which is used in this study, may not fully represent those effects. This is justified by the fact that hub

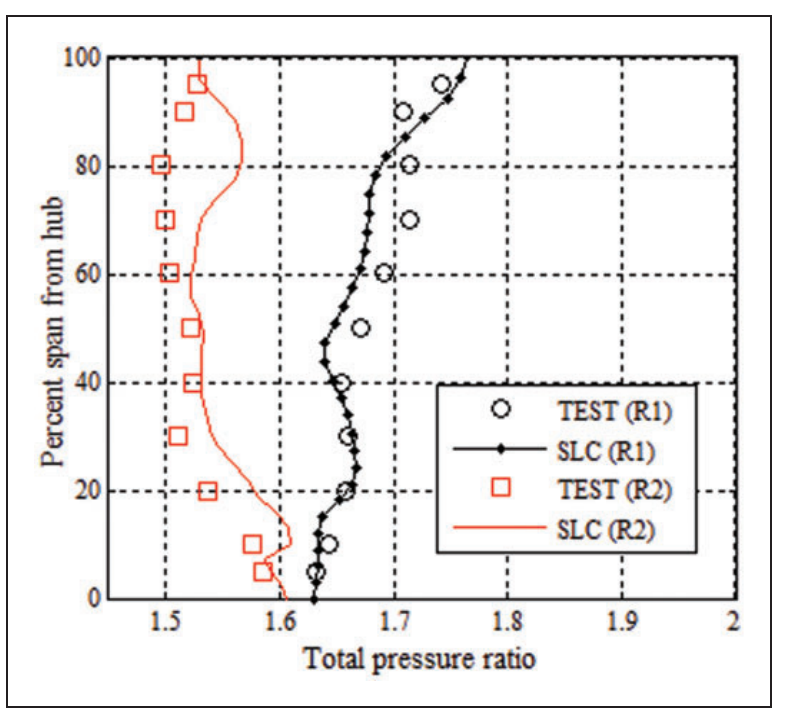

Figure 7. Pressure ratios for the both rotors.

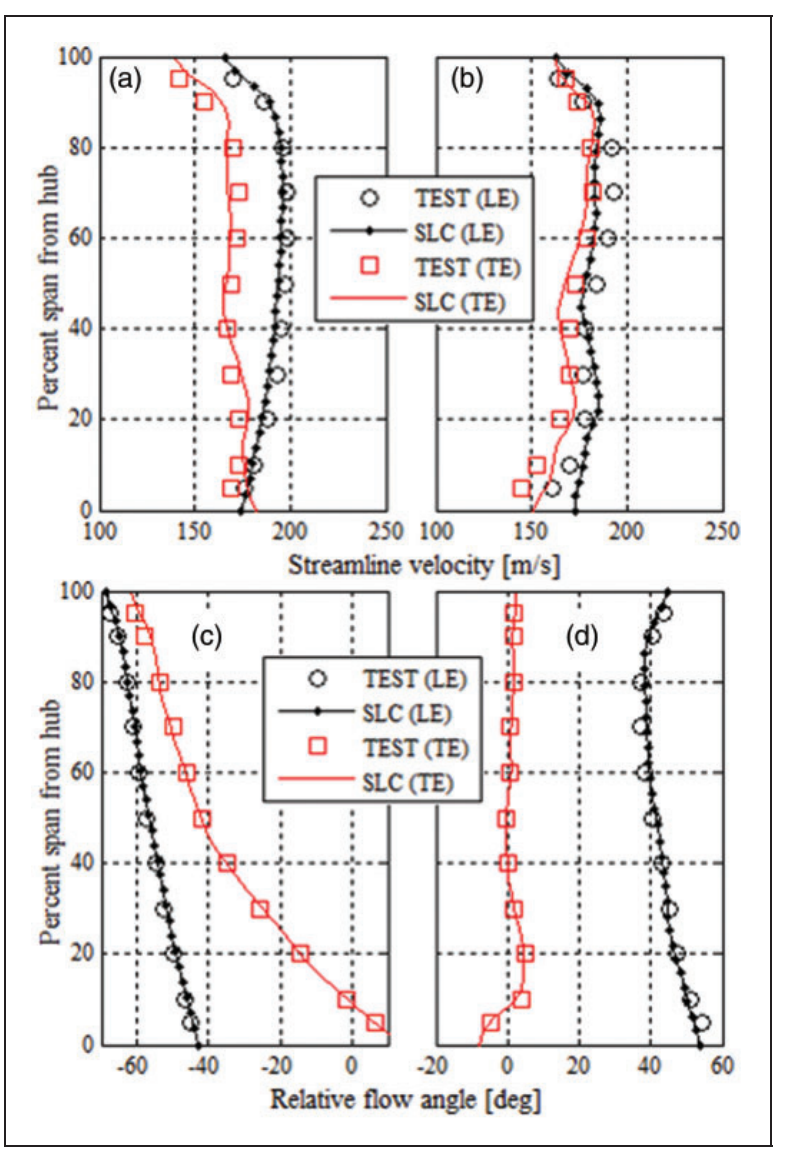

Figure 8. First-stage meridional velocities (a: rotor, b: stator) and relative flow angles (c: rotor, d: stator).

turning is $50^{\circ}$ for the second rotor and $68^{\circ}\left(17^{\circ}\right.$ exit overturning) for the second stator, which correspond to hub design diffusion factors of around $0.55 .{ }^{43}$ Hence, loadings are higher-than-conventional, leading to significantly strong secondary flows. ${ }^{1}$ Moreover, similar discrepancies are also observed in Çetin et al., ${ }^{18}$ who also concluded that mis-prediction of 


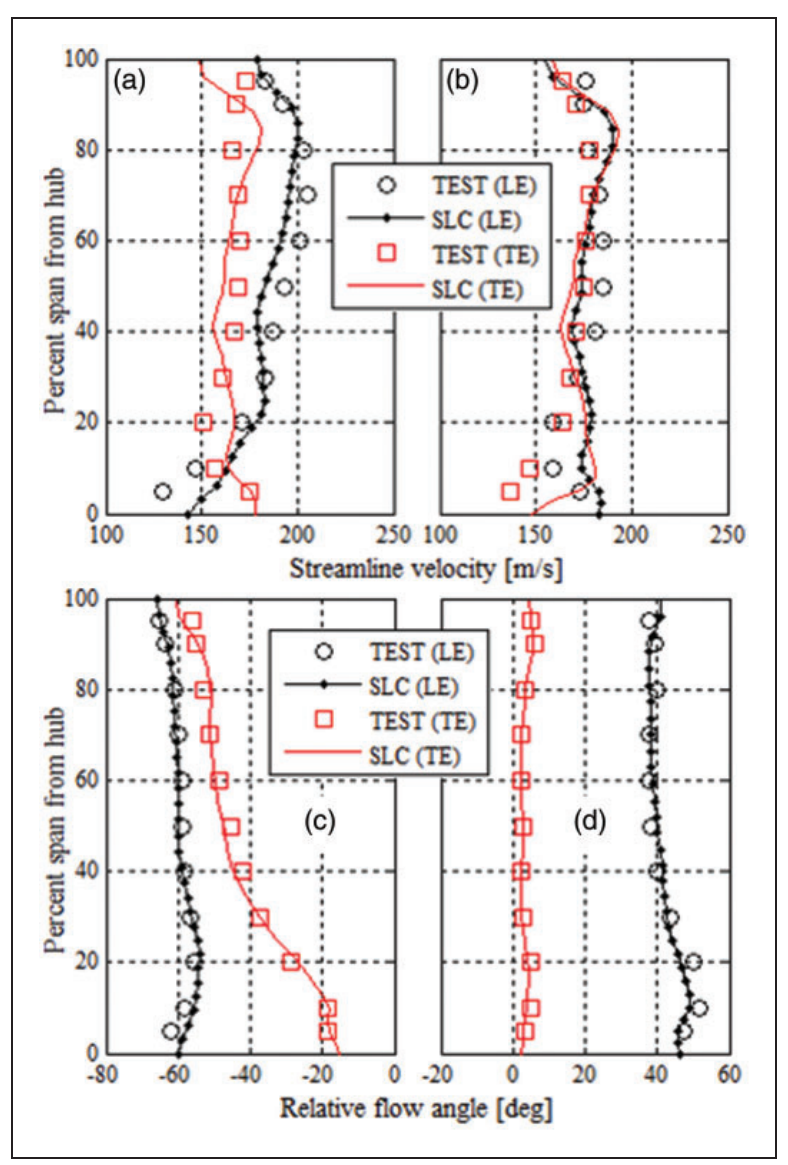

Figure 9. Second-stage meridional velocities (a: rotor, b: stator) and relative flow angles (c: rotor, d: stator).

secondary flows (or mixing) is the main reason. Details of the radial profiles are presented in Figures 7 to 9 .

\section{Custom-designed single-stage fan}

A new transonic fan stage is also designed with the developed SLC program to support the second phase of the validation process that is initiated in the previous section. Considering the fact that NASA 2-stage fan test case given in the previous section operates in off-design regime with strong secondary flow effects, utilization of a more modern fan that operates in the design point with smaller amount of secondary flow effects deemed beneficial. Meridional view and SLC grid of the fan is presented in Figure 10. Standard sealevel static conditions and the mass flow given in Table 5 are specified at the inlet and the calibrated (C) models described in section "Turbomachinery models" are used. The fan is an almost-supersonic and high pressure ratio design with 0.93 hub and 1.41 tip rotor inlet relative Mach numbers and 1.72 total pressure ratio. Estimated efficiency is 0.874 . Stator hub relative Mach number is designed as 0.75 . Rotor solidity is 2.2 at the hub and 1.4 at the tip. Stator solidity is 2.25 at the hub and 1.85 at the tip. Rotor sections are made of MCA profiles, where

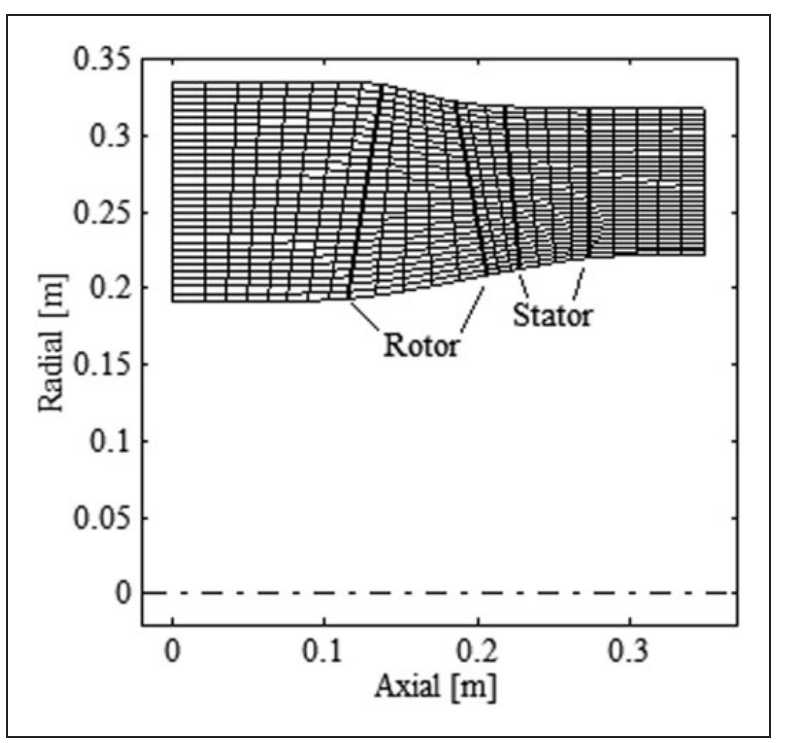

Figure 10. Computational grid of custom-designed fan stage.

Table 5. Overall results.

\begin{tabular}{lccl}
\hline & SLC & 3D CFD & Error (\%) \\
\hline Mass flow (kg/s) & 45.0 & 44.5 & -1.1 \\
Total pressure ratio & 1.72 & 1.705 & -0.9 \\
Efficiency (\%) & 87.4 & 86.7 & -0.8 \\
\hline
\end{tabular}

CFD: computational fluid dynamics; SLC: streamline curvature method.

Table 6. Average errors of radial parameters.

\begin{tabular}{lccc}
\hline & Exit $V_{m}(\%)$ & Exit angle $\left({ }^{\circ}\right)$ & $\begin{array}{c}\text { Total pressure } \\
\text { ratio (\%) }\end{array}$ \\
\hline Rotor I & I.I & 0.2 & 0.4 \\
Stator I & 2.8 & 0.8 & - \\
\hline
\end{tabular}

maximum camber shifts rearwards towards the tip and reaches $70 \%$ of chord-wise distance. Due to lower Mach numbers, stators are made of DCA profiles.

A commercial software, NUMECA FINE/ TURBO, which is specially dedicated to turbomachinery $3 \mathrm{D}$ CFD solution, is used as a benchmark solver. The software is validated against NASA Rotor 37 test case in an AGARD report. ${ }^{44}$ Additional validation with the same test data is also performed by the authors and again the validity is established. Around 240 cells streamwise, 110 cells in tangential direction (between two blades), and 150 elements in spanwise direction are used. For the rotor clearance, 25 cells are generated. y+ values are below unity to resolve boundary layers. In total, there are almost $7 \mathrm{M}$ volumes for the complete stage. Spalart-Allmaras turbulence model is employed and 
all physical properties are modeled as temperature dependent.

Good agreement between the SLC solver and CFD, around or less than $1 \%$ difference, is observed for overall performance, as presented in Table 5 . Table 6 presents average errors in spanwise distributions for spanwise range of 5-95\%, where the error for any quantity " $\mathrm{X}$ " is defined by the average of $100 \times\left|X_{\mathrm{SLC}}-\mathrm{X}_{\mathrm{CFD}}\right| / \mathrm{X}_{\mathrm{CFD}}$. The table indicates less than $3 \%$ difference for the meridional velocity profiles, less than $1^{\circ}$ difference in the relative flow angle profiles and less than $0.5 \%$ difference in the rotor pressure ratio profile. Closer looks at those profiles are presented in Figures 11 and 12, where it is evident that the SLC solver is capable of simulating the considered stage.

\section{GE bypass fan system}

The validation of the complete models, including the developed SLC solver, the new split-flow methodology and the empirical correlations, are validated with GE-NASA split-flow fan (denoted as the advanced technology fan). The tested geometry consists of a fan rotor that have a hub-to-tip ratio of 0.38 , a downstream splitter that divides flow path into bypass and core engine ducts, a bypass outlet guide vane $(\mathrm{OGV})$ and a core inlet guide vane (IGV). The aerodynamic design is documented by Sullivan et al. ${ }^{34}$ In summary, design-intent corrected mass flow rate is $117.9 \mathrm{~kg} / \mathrm{s}$, where a bypass ratio of six is targeted. Bypass and core side fan pressure ratios are 1.83 and 1.73 , respectively. Objective adiabatic efficiency is $84 \%$. Tip relative Mach number of 1.64 and fanface axial Mach number of around 0.76, rather high values, are selected to achieve these targets. Fan rotor is made of custom tailored sections (similar to MCA), but OGV and IGV are made of NACA 65 and DCA profiles, respectively. The post-processed aerodynamic test data is documented by the same authors in another volume of the report. ${ }^{45}$ Only the data with standard short bellmouth inlet is used. Similar to the NASA two-stage fan, the machine works in off-design regime such that the actual mass flow rate is only $114.55 \mathrm{~kg} / \mathrm{s}$ instead of the targeted $117.9 \mathrm{~kg} / \mathrm{s}$. Magnitudes of the measurement uncertainties are similar with the NASA two-stage fan case.

The geometry and SLC grid of the system is presented in Figure 13. Standard sea-level static conditions and the mass flow given in Table 7 are specified at the inlet and both the calibrated (C) and noncalibrated (non-C) models described in section "Turbomachinery models" are used. Comparisons of SLC calculations and the measured data for overall performance are given in Table 7, where good agreement is observed for the calibrated case. Discrepancies are bigger for the spanwise distributions, defined by the average of $100 \mathrm{x}\left|\mathrm{X}_{\mathrm{SLC}}-\mathrm{X}_{\text {test }}\right| / \mathrm{X}_{\text {test }}$ for any " $\mathrm{X}$ " quantity, as presented in Table 8 , but errors are still

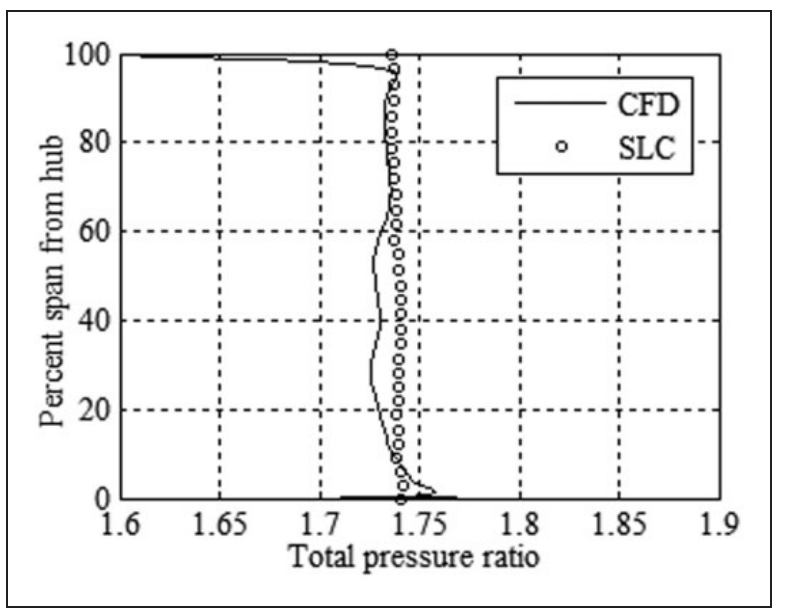

Figure II. Rotor pressure ratio.

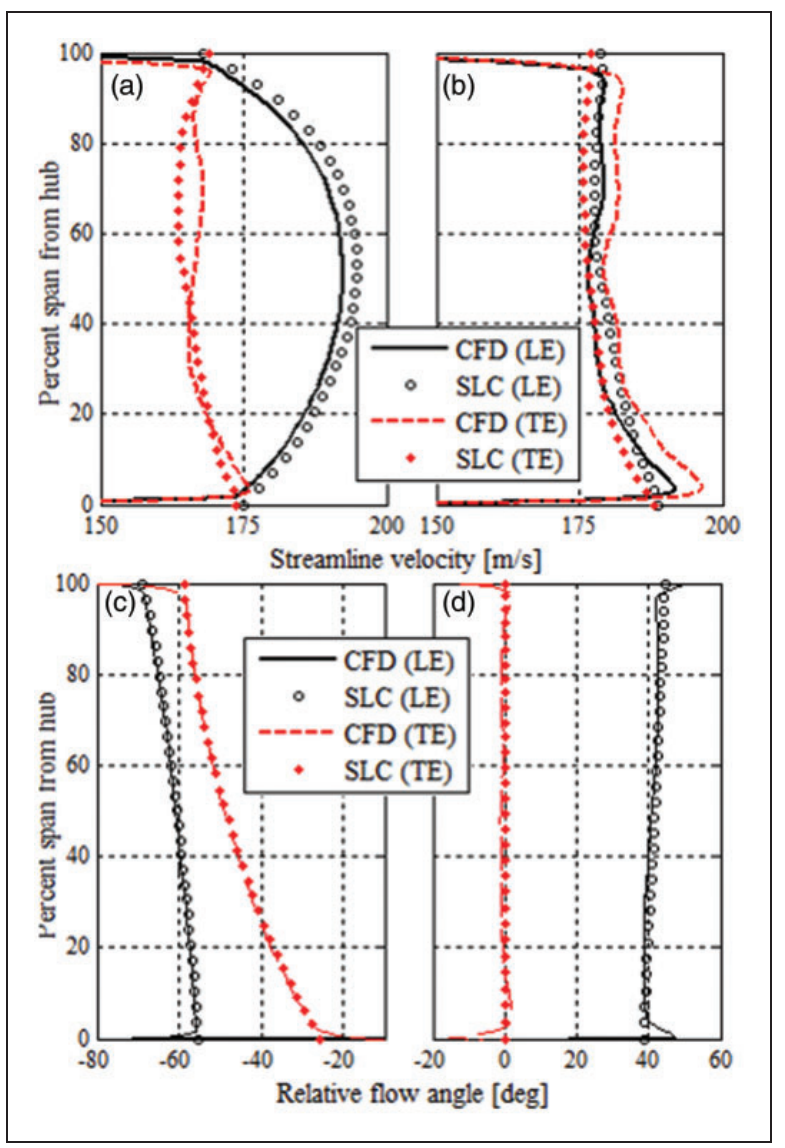

Figure 12. Meridional velocities (a: rotor, b: stator) and relative flow angles (c: rotor, d: stator).

within $6.6 \%$ for meridional velocity, $1.8^{\circ}$ for flow angle and $1.9 \%$ for total pressure ratio. Those distributions are depicted in detail in Figures 14 and 15, where trends are also in good agreement. In these tables and figures, results obtained with the noncalibrated correlations are also presented, where it is evident that the agreement with the test data is much worse, although some local and minor improvements (Table 8) do exist. A close inspection of the total 


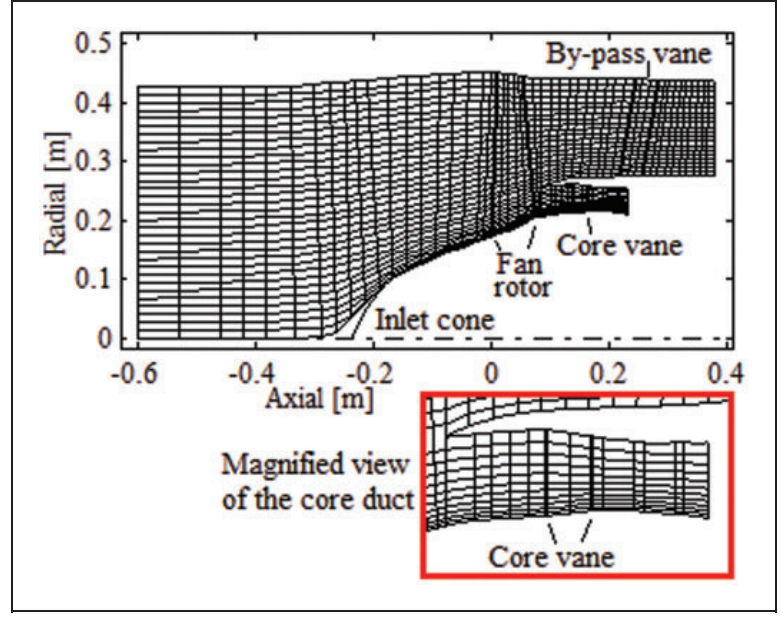

Figure 13. Computational grid of GE-NASA bypass fan.

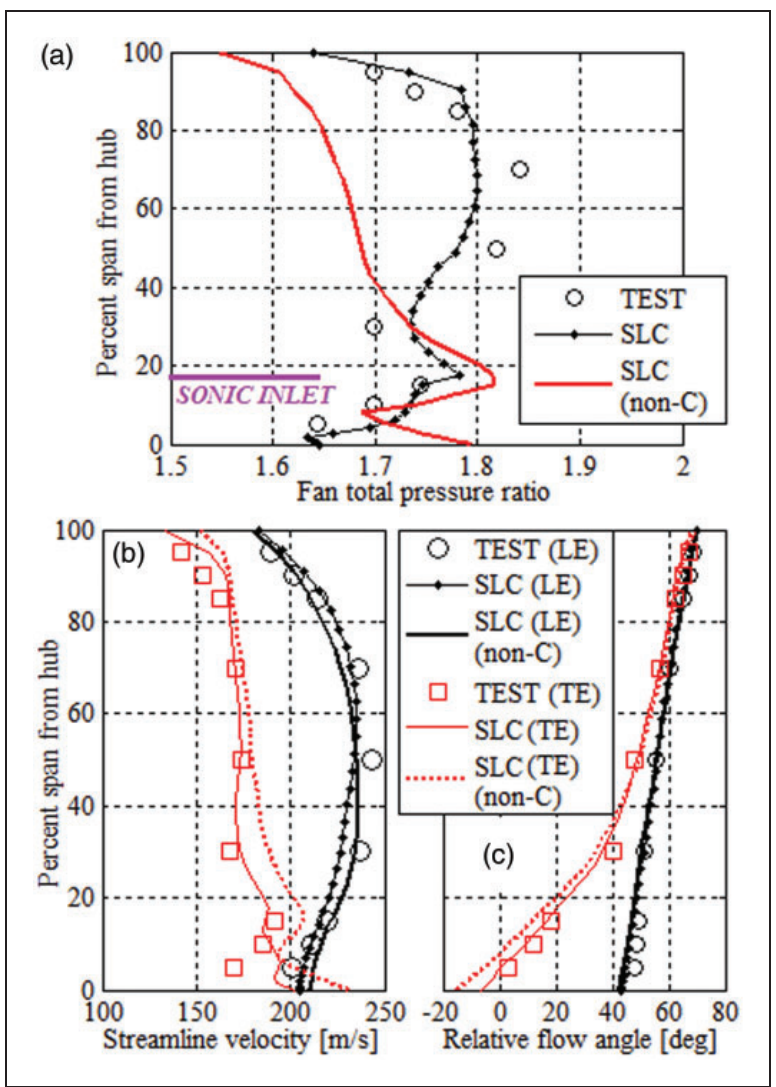

Figure 14. Fan total pressure ratio (a), meridional velocities (b), and relative flow angles (c).

pressure ratio profiles in Figure 14(a) reveals that the most important improvement with the calibrations comes with the reduction of shock losses(item 4 in section "Calibration of the empirical models"), which are excessively high for the noncalibrated case.

Considering the slight off-design operation, deflection of fan blades in high rotational speeds and the empirical models are calibrated for tip relative Mach numbers up to 1.4 in the prior sections but the current case has a tip relative Mach number more than 1.6,
Table 7. Overall results.

\begin{tabular}{lccc}
\hline & Test & $\begin{array}{l}\text { SLC } \\
(\text { C/non-C) }\end{array}$ & $\begin{array}{c}\text { Error (\%) } \\
\text { (C/non-C) }\end{array}$ \\
\hline Mass flow $(\mathrm{kg} / \mathrm{s})$ & 114.55 & 114.55 & $0 \%$ (imposed) \\
Fan total pressure ratio & 1.77 & $1.77 / 1.69$ & $0.1 / 4.5$ \\
Fan efficiency (\%) & 85.7 & $84.0 / 80.6$ & $-2.0 /-6.0$ \\
Bypass ratio & 5.88 & $5.92 / 5.83$ & $0.7 /-0.9$ \\
\hline
\end{tabular}

SLC: streamline curvature method.

Table 8. Average errors of radial parameters.

\begin{tabular}{llll}
\hline & $\begin{array}{l}\text { Exit } V_{m}(\%) \\
(\mathrm{C} / \text { non-C) }\end{array}$ & $\begin{array}{l}\text { Exit angle }\left({ }^{\circ}\right) \\
(\mathrm{C} / \text { non-C) }\end{array}$ & $\begin{array}{l}\text { Total pressure } \\
\text { ratio }(\%) \\
(\mathrm{C} / \text { non-C) }\end{array}$ \\
\hline Fan rotor & $5.1 / 8.9$ & $1.8 / 4.0$ & $1.9 / 5.6$ \\
Bypass OGV & $6.6 / 8.9$ & $1.6 / 1.0$ & - \\
Core IGV & $4.1 / 3.6$ & $1.2 / 1.3$ & - \\
\hline
\end{tabular}

OGV: outlet guide vane; IGV: inlet guide vane.

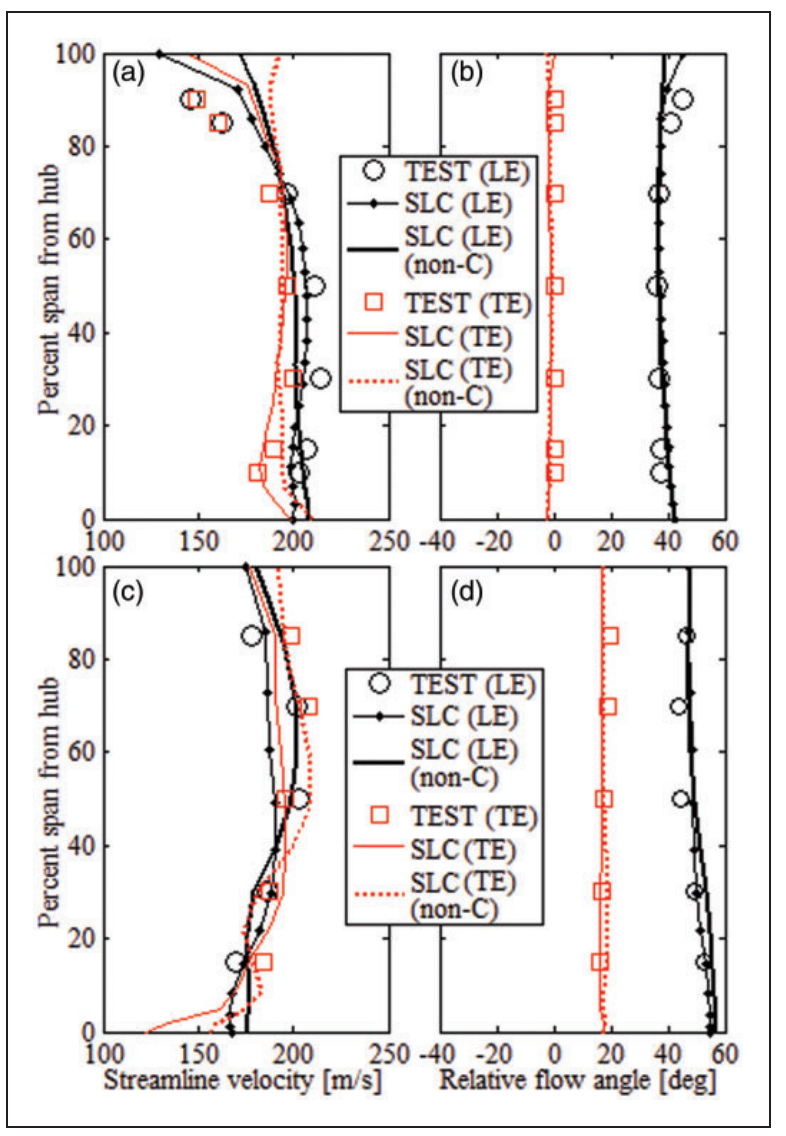

Figure 15. Bypass vane meridional velocities (a) and flow angles (b); core vane meridional velocities (c) and flow angles (d).

the performance of the SLC solver becomes even more evident. In summary, the developed methodology is capable of simulating the current case within engineering level of accuracy. 


\section{Conclusions}

A new and design-oriented streamline curvature through-flow method for split-flow fan modelling capability is developed and validated against experimental and numerical tests. Empirical models for minimum-loss incidence, deviation, loss and blockage are gathered from various sources in the open literature and calibrated by NASA two-stage fan and the author-designed fan test cases, which are both transonic machines with relative tip Mach numbers of around 1.4. The complete models, both the new split-flow method and the empirical models, are ultimately validated on the transonic GE-NASA advanced technology split-flow fan test case.

The developed split-flow capability is shown to be a valid representation of the investigated test cases (sections "Two-dimensional validation of the split-flow method" and "GE bypass fan system"). It can be implemented to existing compressor or single-stream fan SLC through-flow methodologies practically with only minimal algorithmic modifications. In addition to the split-flow capability, the presented set of calibrated empirical models is shown to provide acceptable results in the considered three test cases.

It is expected that the present study will fill the gap in the open literature on inverse design of splitflow fan systems. Extended applications of the method such as sand separation system of turboshaft engines and compressor exit split-flow diffusers are possible.

\section{Acknowledgments}

The authors would like to thank Tusaş Engine Industries for their general support for this work.

\section{Declaration of Conflicting Interests}

The author(s) declared no potential conflicts of interest with respect to the research, authorship, and/or publication of this article.

\section{Funding}

The author(s) received no financial support for the research, authorship, and/or publication of this article.

\section{References}

1. Cumpsty NA. Compressor aerodynamics. 5th ed. Malabar, FL: Krieger Publishing Company, 2004.

2. Shahpar S. Optimisation strategies used in turbomachinery design from an industrial perspective. In: Introduction to optimization and multidisciplinary design in aeronautics and turbomachinery. VKI Lecture Series, 2010.

3. $\mathrm{Wu} \mathrm{CH}$. A general theory of three-dimensional flow in subsonic and supersonic turbomachines of axial, radial and mixed-flow types. NACA TN-2604, 1952.
4. Smith LH. The radial-equilibrium equations of turbomachinery. J Eng Power 1966; 88: 1-12.

5. Novak RA. Streamline curvature computing procedures for fluid flow problems. J Eng Power 1967; 89: 478-490.

6. Marsh H. A digital computer program for the throughflow fluid mechanics in an arbitrary turbomachine using a matrix method. British Aeronautical Research Council Reports and Memoranda, R\&M No.3509, 1968.

7. Hirsch $\mathrm{C}$ and Warzee G. An integrated quasi-3D finite element calculation program for turbomachinery flows. J Eng Power 1979; 101: 141-148.

8. Petrovic MV, Wiedermann A and Banjac MB. Development and validation of a new universal through flow method for axial compressors. In: $A S M E$ turbo expo 2009, Orlando, USA, 2009.

9. Spurr A. The prediction of $3 \mathrm{D}$ transonic flow in turbomachinery using a combined throughflow and blade-toblade time marching method. Int $J$ Heat Fluid Flow 1980; 2: 189-199.

10. Sturmayr A. Evolution of a $3 D$ structured navierstokes solver towards advanced turbomachinery applications. PhD Thesis, University of Vrije, Belgium, 2004.

11. Taddei SR, Larocca F and Bertini F. Euler inverse axisymmetric solution for design of axial flow multistage turbomachinery. In: ASME turbo expo 2010, Glasgow, UK, 2010.

12. Gu F and Anderson MR. CFD-based throughflow solver in a turbomachinery design system. In: $A S M E$ turbo expo 2007, Montreal, Canada, 2007.

13. Simon JF. Contribution to throughflow modeling for axial-flow turbomachines. PhD Thesis, University of Liege, Belgium, 2007.

14. Casey M and Robinson C. A new streamline curvature throughflow method for radial turbomachinery. In: Proceedings of ASME turbo expo 2008, Berlin, Germany, 2008.

15. Denton JD. Throughflow calculations for transonic axial flow turbines. J Eng Power 1978; 100: 212-218.

16. Tiwari P, Stein A and Lin YL. Dual-solution and choked flow treatment in a streamline curvature throughflow solver. In: ASME turbo expo 2011, Vancouver, Canada, 2011.

17. Hirsch $\mathrm{C}$ and Denton JD. Throughflow calculations in axial turbomachinery. AGARD AR-175, 1981.

18. Çetin M, Üçer AŞ, Hirsch C, et al. Application of modified loss and deviation correlations to transonic axial compressors. AGARD R-745, 1987.

19. Lieblein S. Incidence and deviation-angle correlations for compressor cascades. Trans ASME J Basic Eng 1960; 82: 575-587.

20. Lieblein S and Roudebush WH. Theoretical loss relations for low-speed two dimensional cascade flow. NACA TN-3662, 1956.

21. Miller GR, Lewis Jr GW and Hartmann MJ. Shock losses in transonic compressor blade rows. $J$ Eng Power 1961; 83: 235-241.

22. Koch CC and Smith LH. Loss sources and magnitudes in axial-flow compressors. J Eng Power 1976; 98: 411-424. 
23. Horlock JH. The determination of end-wall blockage in axial compressors: A comparison between various approaches. J Turbomachinery 2000; 122: 218-224.

24. Adkins GG and Smith LH. Spanwise mixing in axiaiflow turbomachines. J Eng Power 1982; 104: 97-110.

25. Gallimore SJ. Spanwise mixing in multistage axial flow compressors: Part II - Throughflow calculations including mixing. $J$ Turbomachinery 1986; 108: $10-16$.

26. Wisler DC, Bauer RC and Okiishi TH. Secondary flow, turbulent diffusion, and mixing in axial-flow compressors. J Turbomachinery 1987; 109: 455-469.

27. Dunham J. Modelling of spanwise mixing in compressor through-flow computations. Proc IMechE, Part A: J Power and Energy 1997; 211: 243-251.

28. Mönig R, Mildner F and Röper R. Viscous-flow twodimensional analysis including secondary flow effects. $J$ Turbomachinery 2001; 123: 558-567.

29. Wennerstrom AJ. Design of highly loaded axial-flow fans or compressors: Concepts Eti. 2001.

30. Boyer KM. An improved streamline curvature approach for off-design analysis of transonic compression systems. $\mathrm{PhD}$ Thesis, Virginia Polytechhnic Institute and State University, USA, 2001.

31. Shan P. A mass addition approach to the bypass turbomachine through flow inverse design problem. $J$ Mech Sci Technol 2008; 22: 1921-1925.

32. Calvert WJ and Stapleton AW. Detailed flow measurements and predictions for a three-stage transonic fan. J Turbomachinery 1994; 116: 298-305.

33. Karadimas G. Design of high performance fans using advanced aerodynamic codes. J Turbomachinery 1988; 110: 419-425.

34. Sullivan TJ, Younghans JL and Little DR. Single stage, low noise advanced technology fan. Volume 1: Aerodynamic design. NASA CR-134801, 1976.

35. Sullivan TJ and Parker DE. Design study and performance analysis of a high-speed multistage variablegeometry fan for a variable cycle engine. NASA CR-159545, 1979

36. Sullivan TJ, Luebering GW and Gravitt RD. Energy efficient engine fan test hardware detailed design report. NASA CR-165148, 1980.

37. Aungier RH. Axial flow compressors: A strategy for aerodynamic design and analysis. New York: ASME Press, 2003.

38. Bullock RO and Johnsen IA. Aerodynamic design of axial flow compressors. NASA SP-36, 1965.

39. Kleppler J. Technique to predict stage-by-stage, prestall compressor performance characteristics using a streamline curvature code with loss and deviation correlations. PhD Thesis, University of Tennessee, USA, 1998.

40. Pachidis VA. Gas turbine advanced performance simulation. PhD Thesis, Cranfield University, UK, 2006.

41. Creveling HF. Axial-flow compressor computer program for calculating off-design performance. NASA CR-72472, 1968.

42. ANSYS Fluid Dynamics Verification Manual Release 14.0. Ansys Inc., 2011.

43. Urasek DC, Gorrell WT and Cunnan WS. Performance of two-stage fan having low-aspect-ratio first stage rotor blading. NASA TP-1493, 1979.

44. Dunham J. CFD validation for propulsion system components. AGARD AR-355, 1994.

45. Sullivan TJ, Silverman I and Little DR. Single stage, low noise advanced technology fan. Volume 4: Fan aerodynamics. NASA CR-134892, 1977.

\section{Appendix}

\section{Notation}

$b$

$c$

$C_{1}, C_{2}$

Deq

$F_{q}$

$h$

$H$

$i^{*}$

$i_{c}, i_{s}$

$i_{m}$

\section{K}

$K_{m}$

$K_{\text {sh }}$

M

$O$

$P_{S}$

$P_{T}$

$q$

$r$

$r_{c}$

$R_{c}, R_{s}$

S

$t$

th

T

$T_{T}$

V

W

$\beta$

$\delta^{*}$

$\delta_{V m}$

$\varepsilon$

$\omega$ chord-wise position of maximum turning $(\mathrm{m})$

maximum chordline and camberline distance $(\mathrm{m})$

aerodynamic chord length of a section (m)

coefficients of the loss coefficient

Lieblein equivalent diffusion factor

$\left(W_{\max } / W_{2}\right)$

blade force along a quasi-orthogonal

(N)

average blade height (m)

total enthalpy $(\mathrm{J} / \mathrm{kgK})$

reference incidence $\left(^{\circ}\right)$

choke and stall incidences, respectively $\left(^{\circ}\right)$

Mach-corrected minimum-loss incidence $\left({ }^{\circ}\right)$

blade (metal) angle $\left(^{\circ}\right)$

streamline curvature $\left(=1 / r_{c}\right)(1 / \mathrm{m})$ profile shape factor $(0.7$ for DCA and also MCA)

Mach number

throat opening of a section (m)

static pressure $\left(\mathrm{kg} /\left(\mathrm{ms}^{2}\right)\right)$

total pressure $\left(\mathrm{kg} /\left(\mathrm{ms}^{2}\right)\right)$

quasi-orthogonal direction (m)

radial position $(\mathrm{m})$

streamline radius of curvature (m)

low-speed choke and stall ranges,

respectively $\left(^{\circ}\right)$

entropy $(\mathrm{J} / \mathrm{kgK})$

pitch distance of a section (m)

maximum thickness of a section (m)

static temperature $(\mathrm{K})$

total temperature $(\mathrm{K})$

absolute velocity $(\mathrm{m} / \mathrm{s})$

relative velocity $(\mathrm{m} / \mathrm{s})$

relative flow angle $\left({ }^{\circ}\right)$

stagger angle $\left(^{\circ}\right)$

reference deviation $\left(^{\circ}\right)$

additional deviation $\left({ }^{\circ}\right)$

angle between true and quasi orthogonals (radian)

rotational speed $(\mathrm{rad} / \mathrm{s})$

reference friction total pressure loss coefficient 


$\begin{array}{llll}\varpi_{P T} & \text { relative total pressure loss coefficient } & \theta & \begin{array}{l}\text { tangential direction } \\ \text { leading and trailing edge of a section, } \\ \text { respectively }\end{array} \\ \psi & \text { streamline slope (radian) } & 1,2 & \\ \sigma & \text { modified stagger parameter }\left(^{\circ}\right) & & \\ \rho & \text { solidity }(\mathrm{c} / \mathrm{t}) & \text { Sensity }\left(\mathrm{kg} / \mathrm{m}^{3}\right) & \\ \theta & \text { camber angle, } K_{1}-K_{2}\left(^{\circ}\right) & \text { Superscripts } & \end{array}$

\section{Subscripts}

$m$

meridional (streamline) direction

Quantity in rotation frame of reference 